\title{
12 年 \\ Palladium complexes of aromatic bis-imines and bis-amines: synthesis and evaluation in Heck reactions.
}

\author{
Aretha P.S. Andrade (PG)*, Lucas M. Arantes (PG), Juliana Y. Kadooka (IC), Renato L. \\ Carvalho (IC), Ângelo de Fátima (PQ), Adão A. Sabino (PQ)
}

Grupo de Estudos em Química Orgânica e Biológica (GEQOB), Departamento de Química, ICEx, Universidade Federal de Minas Gerais (UFMG), Belo Horizonte, MG, Brazil, 31270-901.

\section{*arethaprisilva@dout.qui.ufmg.br}

Keywords: Heck reaction, palladium, Schiff base

\section{INTRODUCTION}

Schiff bases have been described as good platforms for obtaining palladium-based organic complexes that work as catalysts for carbon-carbon cross coupling ${ }^{1}$, such as Heck reaction. ${ }^{2}$ This work focused on the synthesis and evaluation of the efficiency of $\mathrm{Pd}$-bis-imines and $\mathrm{Pd}$-bis-amines complexes as catalysts in Heck reaction.

\section{RESULTS AND DISCUSSION}

Three Pd-bis-imines (Pd01 to Pd03) and three Pdbis-amines (Pd01R to Pd03R) complexes were synthesized according to Deligönül and coworkers ${ }^{3}$ and the yields are shown in Figure 1.

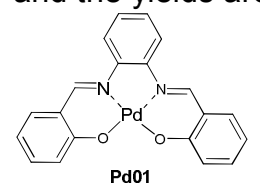

$69 \%$

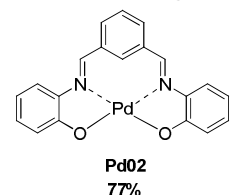

$77 \%$
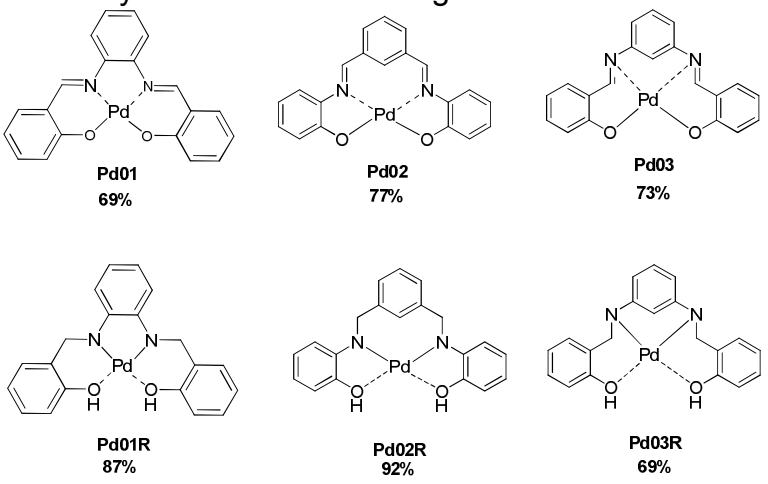

Figure 1. Palladium complexes synthesized and evaluated as catalysts in Heck reaction.

All complexes were employed in Heck reaction of bromobenzene (1) with styrene (2) (Scheme 1). The catalysts efficiency was assessed from the formation of trans-stilbene (3), monitored by gas chromatography coupled to mass spectrometry (GC/MS).

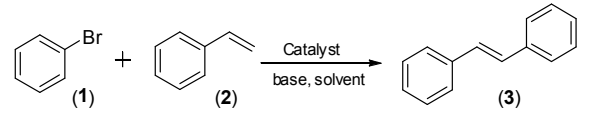

Scheme 1. Heck reaction subject of the present study.

The best yields (Table 1) were achieved when dimethylacetamide (DMA) and sodium carbonate were used as solvent and base, respectively, in reactions maintained for $12 \mathrm{~h}$ in the presence of catalysts at $7.9 \times 10^{-3} \mathrm{~mol} \%$.

Table 1. Efficiency of Pd-bis-imines and Pd-bis-amines complexes as catalysts in Heck reaction ${ }^{\mathrm{a}}$.

\begin{tabular}{ccc}
\hline Catalyst & Yield (\%) & TON $^{\mathbf{b}}$ \\
\hline Pd01 & 69 & 8,619 \\
Pd02 & 77 & 9,577 \\
Pd03 & 74 & 9,163 \\
Pd01R & 87 & 10,764 \\
Pd02R & 92 & 11.359 \\
Pd03R & 69 & 8,547
\end{tabular}

${ }^{a}$ Reaction conditions: bromobenzene at $36 \mathrm{mmol}$, styrene at $54 \mathrm{mmol}$, sodium carbonate at $2 \mathrm{~mol} \%$, catalyst at $7.9 \mathrm{x}$ $10^{-3} \mathrm{~mol} \%$ in DMA under argon atmosphere at $140{ }^{\circ} \mathrm{C}$ for 12 h. ${ }^{\mathrm{b}}$ TON, turnover number.

Overall, Pd-bis-amine complexes were better catalysts in comparison with the ones derived from bis-imines. The highest reaction yield was achieved when Pd02R was employed at $7.9 \times 10^{-3} \mathrm{~mol} \%$, a concentration significantly lower that described in the literature. ${ }^{4}$

\section{CONCLUSION}

All Pd-based complexes were shown to be efficient catalysts for Heck reaction providing the product in yields equal or higher than $70 \%$.

\section{ACKNOWLEDGEMENTS}

This work was supported by FAPEMIG, CAPES and CNPq.

\section{REFERENCES}

1. Jain, V.K.; Jain, L. Coord. Chem. Rev., 2005, 249, 3075.

2.Heck, R. F.; Nolley, J. P. J. Org. Chem., 1972, 37, 2320.

3. Deligönül, N.; Tümer, M.; Serin, S. Trans. Metal Chem., 2006, 31, 920.

4. Lafrance, M.; Fagnou, K. J. Am. Chem. Soc., 2006, 128, 51. 